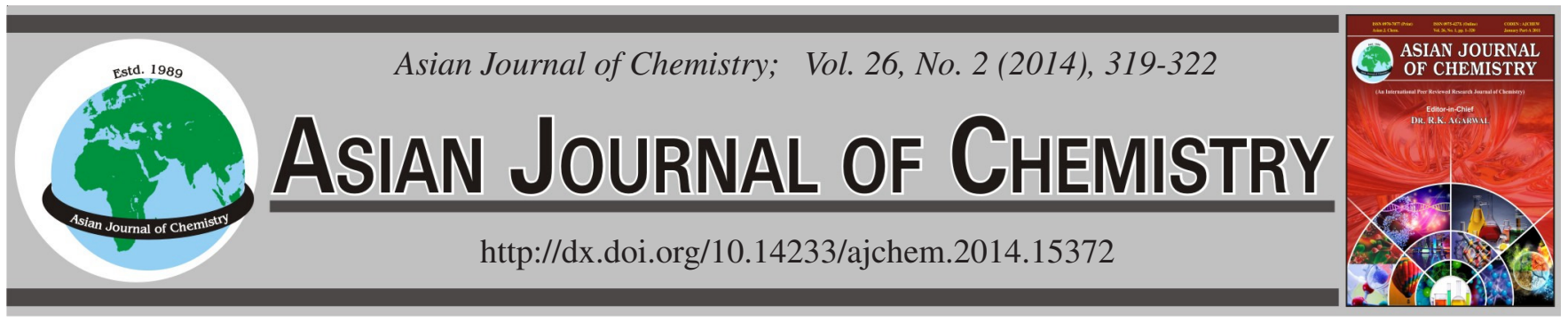

\title{
Enantioselective Hydrogenation of Ethyl Pyruvate Catalyzed by 1,2-Diphenyl-ethylenediamine-Modified Iridium Complex: Effect of Solvent
}

\author{
You Du, Chun Li, Xiaoyun Tan, Haiyan Fu, Xueli Zheng ${ }^{*}$, Ruixiang Li and Hua Chen*
}

Key Lab of Green Chemistry and Technology, Ministry of Education, College of Chemistry, Sichuan University, Chengdu 610064, P.R. China

*Corresponding authors: Tel/Fax: +86 28 85412904; E-mail: scuhchen@163.com

\begin{abstract}
The enantioselective hydrogenation of ethyl pyruvate was explored by a readily available homogeneous iridium catalysis system. It was found that $(1 \mathrm{R}, 2 \mathrm{R})-(+)-1,2-$ diphenyl-ethylenediamine $[(1 \mathrm{R}, 2 \mathrm{R})-\mathrm{DPEN}]$ modified $[\operatorname{Ir}(\mathrm{COD}) \mathrm{Cl}]_{2}(\mathrm{COD}=$ cis, cis-1,5-cyclooctadiene) was highly active for the enantioselective hydrogenation of ethyl pyruvate, and the moderate enantioselectivity of $29 \%$ was obtained (the best value reported by iridium catalysts was $39 \%$ ). NMR spectroscopy proved that hydrogen bond between the solvent and the $\alpha$-carbonyl of ethyl pyruvate would be favor to the enantioselective hydrogenation.
\end{abstract}

Keywords: Enantioselective hydrogenation, Iridium catalysts, Solvent effect, NMR Spectroscopy, Hydrogen bond.

\section{INTRODUCTION}

The enantioselective hydrogenation of methyl pyruvate (the Orito reaction, Scheme-I) was first explored by Orito et al. ${ }^{1}$ with cinchona modified $\mathrm{Pt} / \mathrm{C}$ as catalysts and ( $\mathrm{R}$ )-methyl lactate was successfully obtained with up to $90 \%$ ee. Since then, this reaction was widely studied with cinchona alkaloids modified metal catalysts, such as $\mathrm{Pt}^{2-3}, \mathrm{Ru}^{4}, \mathrm{Rh}^{5}$ and $\mathrm{Pd}^{6}$ catalysts. However, referring to the other metals in Group VIII, only a few has been reported in the enantioselective hydrogenation of $\alpha$-ketoesters so far. In 1994, alkaloid-modified iridium catalysts were first employed in the enantioselective hydrogenation of methyl pyruvate with $90 \%$ conversion and $39 \%$ enantioselectivity by Wells et $a l^{7}$. Then, only a few reports were related ${ }^{8,9}$, because compared to $\mathrm{Pt}$ and $\mathrm{Ru}$ catalysts, the hydrogenation of methyl pyruvate preferred to generate racemic products than chiral products under the Ir catalysis system ${ }^{8}$. Up to date the highest enantioselectivity for iridium catalysts was only $39 \%$, which was obtained by Wells et $a l^{7}$.
As known, the reaction parameters, such as solvent, hydrogen pressure and reaction temperature, have significantly influences on the catalytic activity and enantioselectivity. In the commonly used Pt/cinchona system, different enantioselectivity could be obtained dependent on the solvent used ${ }^{10,11}$. The solvent not only can affect the adsorption of modifier on the surface of the catalysts ${ }^{12}$, but also can interact with the substrates ${ }^{13}$ or even change the conformation of the ligands ${ }^{14}$. Mean while the solvent effect, such as protonation, hydration, or hydrogen bond, is usually involved in the reaction mechanism. The aim of this study is to evaluate the influence of the solvent on both the activity and the enantioselectivity of the iridium catalyzed hydrogenation of $\alpha$-ketoesters.

Herein, the enantioselective hydrogenation of ethyl pyruvate catalyzed by $(1 \mathrm{R}, 2 \mathrm{R})-(+)-1,2$-diphenyl-ethylenediamine $[(1 \mathrm{R}, 2 \mathrm{R})-\mathrm{DPEN}]$ modified $[\mathrm{Ir}(\mathrm{COD}) \mathrm{Cl}]_{2}(\mathrm{COD}=$ cis, cis-1,5cyclooctadiene) was reported. NMR spectroscopy was used to investigate the solvent effect on the reaction. It was found that the system was highly active for the enantioselective hydrogenation of ethyl pyruvate and the hydrogen bond between<smiles>[R]OC(=O)C(C)O</smiles>

(S)

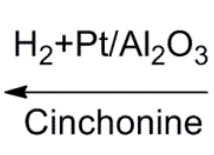<smiles>[R]OC(=O)C(C)=O</smiles>

$$
\text { R: } \mathrm{CH}_{3}, \mathrm{C}_{2} \mathrm{H}_{5}
$$<smiles>[R]OC(=O)[C@H](C)O</smiles>

Scheme-I: Orito's reaction 
the solvent and the $\alpha$-carbonyl of ethyl pyruvate was beneficial to the enantioselective hydrogenation.

\section{EXPERIMENTAL}

$[\mathrm{Ir}(\mathrm{COD}) \mathrm{Cl}]_{2}$ was synthesized according to the procedures reported by Singer et $a l^{15}$. All chemicals, ethyl pyruvate, (1R,2R)-DPEN, (1S,2S)-DPEN, cinchonidine (CD) and cinchonine $(\mathrm{CN}),(1 \mathrm{R}, 2 \mathrm{R})-(+)$-1,2-diamino-cyclohexane [(1R,2R)-DACH], (1S,2S)-(+)-1,2-diamino-cyclohexane [(1S,2S)-DACH], N-[(1R,2R)-2-amino-1,2-diphenylethyl]-4methyl-benzenesulfonamide [(1R,2R)-Ts-DPEN], $\mathrm{H}_{2} \mathrm{IrCl}_{6} \cdot 6 \mathrm{H}_{2} \mathrm{O}$, cis, cis-1,5-cyclooctadiene (COD) were reagent grade and used as purchased without further purification. All solvents were purified and dried according to standard methods. ${ }^{1} \mathrm{H}$ NMR spectra were recorded on Bruker Avance II-400 MHz with reference to TMS as the internal standard, $J$-values are in Hz. Products were analyzed by GC-960 instrument with an FID detector and $\beta$-DEX120 capillary column $(0.25 \mathrm{~mm} \times 0.25 \mu \mathrm{m} \times 30 \mathrm{~m})$.

Hydrogenation of ethyl pyruvate: The hydrogenation of ethyl pyruvate was performed in a $60 \mathrm{~mL}$ steel autoclave with magnetic stirring. The desired amounts of substrate, catalyst, ligand and solvent were added into the autoclave, which was then sealed and purged 3 times with hydrogen. Then, the hydrogen pressure was increased to desired value and the mixture was stirred under the preset temperature. After the reaction, the products were analyzed by GC. The ee' value was calculated according to the following:

$$
\text { ee }(\%)=100 \times(\mathrm{S}-\mathrm{R}) /(\mathrm{S}+\mathrm{R})
$$

\section{RESULTS AND DISCUSSION}

The enantioselective hydrogenation of ethyl pyruvate was investigated with three kinds of iridium complexes and seven $\mathrm{N}, \mathrm{N}$ ligands as shown in Table-1. From Table-1, it can be seen that $[\operatorname{Ir}(\mathrm{COD}) \mathrm{Cl}]_{2}$ with the central metal iridium in a low oxidation state, gave a relatively higher activity and enantioselectivity compared to other precursors $\operatorname{Ir}(\mathrm{acac})_{3}$ and $\mathrm{H}_{2} \mathrm{IrCl}_{6} \cdot 6 \mathrm{H}_{2} \mathrm{O}$ (entry 1-3). Therefore, $[\mathrm{Ir}(\mathrm{COD}) \mathrm{Cl}]_{2}$ was selected as the catalyst precursor in the other experiments. From entry 5 and 6 , it can be seen that the commonly used ligands in the enantioselective hydrogenation of ethyl pyruvate, cinchonidine (CD) and cinchonine $(\mathrm{CN})$, could accelerate the reaction rate ${ }^{16}$, but resulted in racemic products. Among the seven-examined N,N ligands (1R, 2R)-DPEN, (1S, 2S)-DPEN, (1R, 2R)-TsDPEN, (1R, 2R)-DACH and (1S, 2S)-DACH, the (1R, 2R)-
DPEN was found to be the most outstanding (entry 3-9). When $(1 \mathrm{R}, 2 \mathrm{R})-\mathrm{DPEN}$ and $[\operatorname{Ir}(\mathrm{COD}) \mathrm{Cl}]_{2}$ were used as ligand and catalyst precursor, respectively, $70 \%$ of conversion with $29 \%$ ee could be achieved, which was comparable with the results reported by Wells et $a l^{7}$.

In an attempt to clarify the solvent effect on the enantioselective hydrogenation of ethyl pyruvate, the hydrogenation of ethyl pyruvate was investigated in different solvents and the results were summarized in Table-2. Both the conversion and enantioselectivity were highly dependent on the solvent. In the commonly used solvents in Pt-catalyzed heterogeneous hydrogenation ${ }^{17}$, such as acetic acid, toluene and dichloromethane, etc., only lower conversion (10-44\%) and enantioselectivity (0-14\%) were obtained (entry 1-6). While the alcoholic solvents, such as methanol, ethanol, 1-propanol and 1-butanol, were good solvent for this reaction. Wells et al. ${ }^{7}$ and Liu et al. ${ }^{8}$ reported that the moderate conversion and about $29 \%$ ee in the hydrogenation of ethyl pyruvate. In those solvents, the highest activity and enantioselectivity were observed in the most polar methanol and lower activity or enantioselectivity was detected in the less polar ethanol and 1-propanol, it seems that the conversion and the enantioselectivity trend to decrease as the polarity of the solvents decreased (entry 7-10). However, when the more polar water was added in the methanol as solvent, the conversion and the ee' value were dropped quickly as the amount of water increased

\begin{tabular}{|c|c|c|c|}
\hline \multicolumn{4}{|c|}{$\begin{array}{c}\text { TABLE-2 } \\
\text { ENANTIOSELECTIVE HYDROGENATION OF ETHYL } \\
\text { PYRUVATE IN VARIOUS SOLVENTS }\end{array}$} \\
\hline Entry & Solvent & $\begin{array}{c}\text { Conversion } \\
(\%)\end{array}$ & $\begin{array}{c}\text { Enantioselectivity } \\
(\%)^{\mathrm{b}}\end{array}$ \\
\hline 1 & Acetic acid & 44 & 5 \\
\hline 2 & Acetone & 26 & 14 \\
\hline 3 & Ethyl acetate & 19 & 6 \\
\hline 4 & THF & 13 & 0 \\
\hline 5 & Dichloromethane & 10 & 1 \\
\hline 6 & Toluene & 10 & 0 \\
\hline 7 & Methanol & 70 & 29 \\
\hline 8 & Ethanol & 62 & 25 \\
\hline 9 & 1-Propanol & 36 & 23 \\
\hline 10 & 1-Butanol & 27 & 22 \\
\hline 11 & Methanol/water $(6 / 1)^{c}$ & 44 & 22 \\
\hline 12 & Methanol/water(3/1) & 36 & 16 \\
\hline 13 & Methanol/water(1/1) & 17.6 & 14 \\
\hline 14 & Water & 11.6 & 10 \\
\hline \multicolumn{4}{|c|}{$\begin{array}{l}{ }^{a} \text { Reaction conditions: substrate/Ir/ligand =1000:1:2, [Ir]: } 0.003 \mathrm{mmol} \text {, } \\
25^{\circ} \mathrm{C}, 1 \mathrm{MPa}, 2 \mathrm{~h} \\
{ }^{\mathrm{b}} \mathrm{S} \text {-ethyl lactate in excess } \\
{ }^{\mathrm{c}} \text { Volume ratio }\end{array}$} \\
\hline
\end{tabular}

TABLE-1

ENANTIOSELECTIVE HYDROGENATION OF ETHYL PYRUVATE WITH DIFFERENT IRIDIUM COMPLEXES AND LIGANDS ${ }^{a}$

\begin{tabular}{cccccc}
\hline Entry & Iridium complex & Ligand & Con $(\%)$ & ee $(\%)$ & Configuration \\
\hline 1 & {$[\operatorname{Ir}(\mathrm{COD}) \mathrm{Cl}]_{2}$} & $(1 \mathrm{R}, 2 \mathrm{R})-\mathrm{DPEN}$ & 70 & 29 & $\mathrm{~S}$ \\
2 & $\mathrm{Ir}(\mathrm{acac})_{3}$ & $(1 \mathrm{R}, 2 \mathrm{R})-\mathrm{DPEN}$ & 11 & 8 & $\mathrm{~S}$ \\
3 & $\mathrm{H}_{2} \mathrm{IrCl}{ }_{6} \cdot \mathrm{H}_{2} \mathrm{O}$ & $(1 \mathrm{R}, 2 \mathrm{R})-\mathrm{DPEN}$ & 6 & 4 & $\mathrm{~S}$ \\
4 & {$[\mathrm{Ir}(\mathrm{COD}) \mathrm{Cl}]_{2}$} & $(1 \mathrm{~S}, 2 \mathrm{~S})-\mathrm{DPEN}$ & 38 & 5 & $\mathrm{R}$ \\
5 & {$[\mathrm{Ir}(\mathrm{COD}) \mathrm{Cl}]_{2}$} & $\mathrm{CD}$ & 72 & 0 & - \\
6 & {$[\operatorname{Ir}(\mathrm{COD}) \mathrm{Cl}]_{2}$} & $\mathrm{CN}$ & 99 & 7 & $\mathrm{~S}$ \\
7 & {$[\mathrm{Ir}(\mathrm{COD}) \mathrm{Cl}]_{2}$} & $(1 \mathrm{R}, 2 \mathrm{R})-\mathrm{TS}-\mathrm{DPEN}$ & 94 & 10 & $\mathrm{~S}$ \\
8 & {$[\mathrm{Ir}(\mathrm{COD}) \mathrm{Cl}]_{2}$} & $(1 \mathrm{R}, 2 \mathrm{R})-\mathrm{DACH}$ & 76 & 13 & $\mathrm{~S}$ \\
9 & {$[\operatorname{Ir}(\mathrm{COD}) \mathrm{Cl}]_{2}$} & $(1 \mathrm{~S}, 2 \mathrm{~S})-\mathrm{DACH}$ & 77 & 9 & $\mathrm{R}$ \\
\hline
\end{tabular}

${ }^{a}$ Reaction conditions: substrate/Ir/ligand $=00 / 1 / 2$, [Ir]: $0.003 \mathrm{mmol}, 25^{\circ} \mathrm{C}, 1 \mathrm{MPa}, 2 \mathrm{~h}$, metanol: $2 \mathrm{~mL}$ 
(entry 11-14). As the solvent, methanol is of lower polarity than water, but higher activity and enantioselectivity were observed in methanol, which indicated that the activity and the enantioselectivity were not only dependent on the polarity of the solvent. The interaction between the solvent and the ethyl pyruvate might occur during the hydrogenation process and dramatically influence the conversion and the enantioselectivity ${ }^{13,14}$.

In order to comprehend the interaction between the solvent and the ethyl pyruvate, ${ }^{1} \mathrm{H}$ NMR characterization of ethyl pyruvate in different solvents were investigated and the results were shown in Fig. 1. ${ }^{1} \mathrm{H}$ NMR of ethyl pyruvate in $\mathrm{CDCl}_{3}$ (spectrum A), three sets of characteristic peaks, including a quartet centered at $4.30 \mathrm{ppm}\left(\mathrm{CH}_{2}\right.$ protons of the ethoxyl group $\left.\mathrm{OCH}_{2} \mathrm{CH}_{3}, \mathrm{H}_{\mathrm{a}}\right)$, a singlet at $2.45 \mathrm{ppm}\left(\mathrm{CH}_{3}\right.$ protons attached on keto-carbonyl group $\mathrm{CH}_{3} \mathrm{CO}, \mathrm{Hb}$ ) and a triplet centered at $1.34 \mathrm{ppm}\left(\mathrm{CH}_{3}\right.$ protons of the ethoxyl group $\mathrm{OCH}_{2} \mathrm{CH}_{3}, \mathrm{H}_{\mathrm{c}}$ ), were observed ${ }^{18}$. While all of those peaks divided into two parts with different chemical shifts in $\mathrm{CD}_{3} \mathrm{OD}$, $\mathrm{D}_{2} \mathrm{O}$ or mixture thereof (spectra B-F), especially for the singlet of $\mathrm{H}_{\mathrm{b}}$, which split into two singlet at $2.40 \mathrm{ppm}$ and more upfield $1.47 \mathrm{ppm}$ in $\mathrm{CD}_{3} \mathrm{OD}$. This phenomenon may hint that the hydrogen bond was probably formed between the solvent and ethyl pyruvate ${ }^{19}$. The presence of the hydrogen bond between $\mathrm{CD}_{3} \mathrm{OD}$ and the $\alpha$-carbonyl group of ethyl pyruvate ${ }^{20}$, could somehow weaken the shielding effect of the $\alpha$-carbonyl oxygen on the adjacent methyl group and the signal of the $\mathrm{CH}_{3}$ adjacent to $\alpha$-carbonyl group upshifted to $1.47 \mathrm{ppm}$. Theoretically, the ethoxy group, due to its electron-donating properties, would make the carbonyl oxygen of the ester group more electron rich and increase the hydrogen accepting capability of the ester carbonyl $^{21}$, thus make the carbonyl oxygen of the ester group more inclined to form hydrogen bond with the solvent. However, more obvious change was observed in the chemical shift of $\mathrm{H}_{\mathrm{b}}$ (from $2.40 \mathrm{ppm}$ to $1.47 \mathrm{ppm}$ ), instead of $\mathrm{H}_{\mathrm{a}}$ and $\mathrm{H}_{\mathrm{c}}$, which are closer to ester group. This phenomenon indicated that the hydrogen bond might be formed between the $\alpha$-carbonyl group of ethyl pyruvate and the solvent had a much more significant influence on the adjacent methyl. And the likely model of hydrogen bond between the $\alpha$-carbonyl group of ethyl pyruvate and the solvent was assumed in Fig. 2a.<smiles>[R]O[O+]=C(C)C(=O)OCC</smiles><smiles>CCOC(=O)C(C)(O)O</smiles>

Fig. 2. Hydrogen bond and hydrate of ethyl pyruvate

It is noted that the two parts of the signal for $\mathrm{H}_{\mathrm{c}}$ overlapped, so their peak areas were difficult to be calculated. Instead, the peak areas for two division parts of the protons $\mathrm{H}_{\mathrm{a}}$ and $\mathrm{H}_{\mathrm{b}}$ in the substrate molecules were calculated respectively and one part was affected by the hydrogen bond with solvent (hydrogen bonding part), another was not affected by the hydrogen bond with solvent (non-hydrogen bonding part). Table-3 summarized the peak areas and their ratios for the two parts of $\mathrm{H}_{\mathrm{a}}$ and $\mathrm{H}_{\mathrm{b}}$, respectively. According to the data in Table-3, we can estimate the proportion of reactant molecules which have formed hydrogen bond with the solvent. As for ${ }^{1} \mathrm{H}$ NMR of $-\mathrm{COCH}_{3}$ in $\mathrm{CD}_{3} \mathrm{OD}$, the area ratio of hydrogen bonding part (1.47 ppm) to non-hydrogen bonding part (2.40 ppm) is 6.12 , which means that about $86 \%$ of ethyl pyruvate formed the hydrogen bond with $\mathrm{CD}_{3} \mathrm{OD}$. The ratio followed a decreasing sequence as the $\mathrm{CD}_{3} \mathrm{OD} / \mathrm{D}_{2} \mathrm{O}$ ratio decreased: $\mathrm{CD}_{3} \mathrm{OD}(6.12)$, $\mathrm{CD}_{3} \mathrm{OD}: \mathrm{D}_{2} \mathrm{O}=6$ (5.34), $\mathrm{CD}_{3} \mathrm{OD}: \mathrm{D}_{2} \mathrm{O}=3$ (4.76), $\mathrm{CD}_{3} \mathrm{OD}: \mathrm{D}_{2} \mathrm{O}$

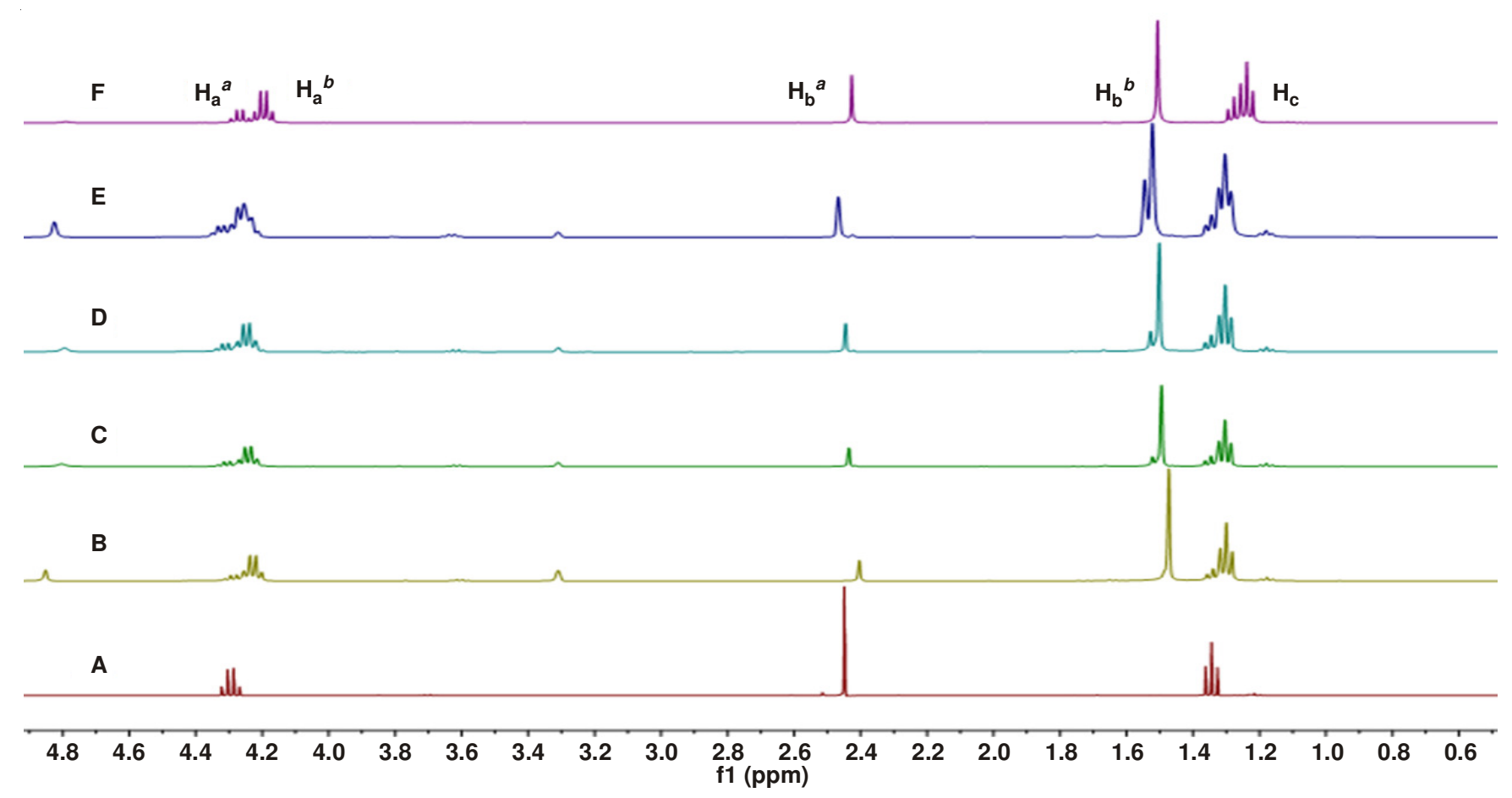

Fig. 1. ${ }^{1} \mathrm{H}$ NMR spectra of ethyl pyruvate in different solvents: $(\mathrm{A}) \mathrm{CDCl}_{3}(\mathrm{~B}) \mathrm{CD}_{3} \mathrm{OD}(\mathrm{C}) \mathrm{CD}_{3} \mathrm{OD}: \mathrm{D}_{2} \mathrm{O}=6: 1,(\mathrm{D}) \mathrm{CD} \mathrm{DD}_{3} \mathrm{OD} \mathrm{D}_{2} \mathrm{O}=3: 1(\mathrm{E}) \mathrm{CD} \mathrm{OD}_{3}: \mathrm{D}_{2} \mathrm{O}=1: 1$ (F) $\mathrm{D}_{2} \mathrm{O}$ (a) the protons of non-hydrogen bonding part (b) the protons of hydrogen bonding part 
$=1$ (4.63), $\mathrm{D}_{2} \mathrm{O}$ (2.82). And the activity and enantioselectivity were also decreased as this trend, the conversion decreased from 70 to $12 \%$ and the enantioselectivity decreased from 29 to $10 \%$. Although, compared to methanol (or $\mathrm{CD}_{3} \mathrm{OD}$ ), water is a stronger hydrogen bond donor, it seems that the methanol might be easier to form hydrogen bond with the carbonyl oxygen of ethyl pyruvate. The negative effect of water was probably due to rapid hydration of the activated ketone, as reported by Baiker et al. ${ }^{22}$ that even 0.8 vol \% water in the system could lead to approximate $1 \%$ ethyl pyruvate hydrated (Fig. 2b). The hydrogenation of $\mathrm{C}-\mathrm{OH}$ bond is much slower compared to ketone ${ }^{23}$ and the hydration would hinder the coordination of $\alpha$-carbonyl with iridium complex, so the presence of trace water caused the activity and the enantioselectivity to decrease. When acetic acid was used as solvent, though the hydrogen bond could be formed between the acetic acid and the ethyl pyruvate, the $\mathrm{NH}_{2}$ group of the ligand could be protonated significantly by acetic acid, which was unfavorable for the coordination of ligand with iridium complex. So under our reaction conditions, the hydrogen bond between the $\alpha$-carbonyl group of ethyl pyruvate and the solvent could be formed easily in $\mathrm{MeOH}$ (or $\mathrm{CD}_{3} \mathrm{OD}$ ), the $\alpha$-carbonyl was activated by the hydrogen bond and could be hydrogenated more easily. Therefore, the highest conversion and enantioselectivity of ethyl pyruvate were observed in methanol.

\begin{tabular}{|c|c|c|c|c|c|c|}
\hline \multicolumn{7}{|c|}{$\begin{array}{c}\text { TABLE-3 } \\
\text { PEAK AREAS AND AREA RATIOS FOR } \\
\text { THE TWO PARTS OF } \mathrm{H}_{\mathrm{a}} \text { AND } \mathrm{H}_{\mathrm{b}}\end{array}$} \\
\hline \multirow{2}{*}{ Solvent } & \multicolumn{3}{|c|}{$-\mathrm{OCH}_{2-}$} & \multicolumn{3}{|c|}{$\mathrm{CH}_{3} \mathrm{CO}-$} \\
\hline & $\mathrm{H}_{\mathrm{a}}^{\mathrm{b}}$ & $\mathrm{H}_{\mathrm{a}}^{\mathrm{a}}$ & $\mathrm{H}_{\mathrm{a}}^{\mathrm{b}} / \mathrm{H}_{\mathrm{a}}^{\mathrm{a}}$ & $\mathrm{H}_{\mathrm{b}}{ }^{\mathrm{b}}$ & $\mathrm{H}_{\mathrm{b}}{ }^{\mathrm{a}}$ & $\mathrm{H}_{\mathrm{b}}^{\mathrm{b}} / \mathrm{H}_{\mathrm{b}}{ }^{\mathrm{a}}$ \\
\hline $\mathrm{CD}_{3} \mathrm{OD}$ & 1.60 & 0.40 & 4.00 & 2.57 & 0.42 & 6.12 \\
\hline $\begin{array}{c}\mathrm{CD}_{3} \mathrm{OD}: \mathrm{D}_{2} \mathrm{O} \\
\quad=6: 1\end{array}$ & 1.57 & 0.40 & 3.93 & 2.51 & 0.47 & 5.34 \\
\hline $\begin{array}{c}\mathrm{CD}_{3} \mathrm{OD}: \mathrm{D}_{2} \mathrm{O} \\
=3: 1\end{array}$ & 1.51 & 0.50 & 3.02 & 2.57 & 0.54 & 4.76 \\
\hline $\begin{array}{c}\mathrm{CD}_{3} \mathrm{OD}: \mathrm{D}_{2} \mathrm{O} \\
=1: 1\end{array}$ & 1.46 & 0.55 & 2.65 & 2.41 & 0.52 & 4.63 \\
\hline $\mathrm{D}_{2} \mathrm{O}$ & 1.43 & 0.59 & 2.42 & 2.20 & 0.78 & 2.82 \\
\hline
\end{tabular}

athe integral area for the protons of non-hydrogen bonding part

${ }^{b}$ the integral area for the protons of hydrogen bonding part

\section{Conclusion}

In conclusion, we have demonstrated a highly active (1R, $2 \mathrm{R})$-DPEN modified $[\operatorname{Ir}(\mathrm{COD}) \mathrm{Cl}]_{2}$ for the enantioselective hydrogenation of ethyl pyruvate, $29 \%$ ee was obtained by our catalysis system (up to date, the best value of enantio- selectivity was $39 \%$ for iridium catalysts). NMR experiments have revealed that the hydrogen bond between the solvent and the $\alpha$-carbonyl group of ethyl pyruvate facilitated this hydrogenation reaction.

\section{ACKNOWLEDGEMENTS}

Financial support of the National Science Talents Fund for Research Training and Research Ability Improvement project (J1103315) was gratefully acknowledged.

\section{REFERENCES}

1. Y. Orito, S. Imai. S. Niwa and N.-G. Hung, J. Synth. Org. Chem., 37, 173 (1979)

2. M.U. Azmat, Y. Guo, Y. Guo, Y. Wang and G. Lu, J. Mol. Catal. A: Chem., 336, 42 (2011).

3. Z. Chen, Z. Guan, M. Li, Q. Yang and C. Li, Angew. Chem. Int. Ed., 50, 4913 (2011).

4. M. Jahjah, M. Alame, S. Pellet-Rostaing and M. Lemaire, Tetrahedron Asymm., 18, 2305 (2007).

5. Z. Herseczki, I. Gergely, C. Hegedüs, Á. Szöllosy and J. Bakos, Tetrahedron Asymm., 15, 1673 (2004).

6. M. Vago, F.J. Williams and E.J. Calvo, Electrochem. Commun., 9, 2725 (2007).

7. K.E. Simons, A. Ibbotson, P. Johnston, H. Plum and P.B. Wells, J. Catal., 150, 321 (1994).

8. X.B. Zuo, H.F. Liu and C. Yue, J. Mol. Catal. A: Chem., 147, 63 (1999).

9. T. Marzialetti, M. Oportus, D. Ruiz, J.L.G. Fierro and P. Reyes, Catal. Today, 133, 711 (2008).

10. H.U. Blaser, H.P. Jalett and J. Wiehl, J. Mol. Catal., 68, 215 (1991).

11. E. Toukoniitty, V. Nieminen, A. Taskinen, J. Päivärinta, M. Hotokka and D.Y. Murzin, J. Catal., 224, 326 (2004).

12. H.U. Blaser, H.P. Jalett, D.M. Monti, J.F. Reber and J.T. Wehrli, Stud. Surf. Sci. Catal., 41, 153 (1988).

13. B. Minder, T. Mallat, P. Skrabal and A. Baiker, Catal. Lett., 29, 115 (1994).

14. J.L. Margitfalvi and M. Hegedus, J. Mol. Catal. A: Chem., 107, 281 (1996).

15. G. Winkhaus and H. Singer, Chem. Ber., 99, 3610 (1966).

16. Y.L. Huang, J.R. Chen, H. Chen, R.X. Li, Y.Z. Li, L.E. Min and X.J. Li, J. Mol. Catal. A: Chem., 170, 143 (2001).

17. J.T. Wehrli, A. Baiker, D.M. Monti, H.U. Blaser and H.P. Jalett, J. Mol. Catal., 57, 245 (1989).

18. P.A. Manis and M.W. Rathke, J. Org. Chem., 45, 4954 (1980).

19. F. Hoxha, T. Mallat and A. Baiker, J. Catal., 248, 11 (2007).

20. A. Vargas, F. Hoxha, N. Bonalumi, T. Mallat and A. Baiker, J. Catal., 240, 203 (2006).

21. A. Taskinen, V. Nieminen, E. Toukoniitty, D. Y. Murzin and M. Hotokka, Tetrahedron, 61, 8109 (2005).

22. M. von Arx, T. Mallat and A. Baiker, Angew. Chem. Int. Ed., 40, 2302 (2001).

23. F. Notheisz and M. Bartok, Fine Chemical through Heterogeneous Catalysis, Wiley-VCH, Weinheim, p. 415 (2001). 